\title{
Association of hsa-miR-145 overexpression in human testicular cells with male infertility
}

\author{
LIYUAN ZHANG ${ }^{1}$, XIANPING DING ${ }^{1,2}$, SHUANGSHUANG NIE $^{1}$, JESSE LI-LING $^{1}$, \\ YUPING ZHANG ${ }^{1}$, HUI ZHANG ${ }^{1}$, LIN CHEN $^{1}$, LINGXIAO LI ${ }^{1}$ and MIN DING ${ }^{1}$ \\ ${ }^{1}$ Bio-resource Research and Utilization Joint Key Laboratory of Sichuan-Chongqing, Institute of Medical Genetics, \\ College of Life Science, Sichuan University, Chengdu, Sichuan 610064; \\ ${ }^{2}$ Biotechnology Academy of Nanchuan, Nanchuan, Chongqing, 408400 P.R. China
}

Received March 19, 2014; Accepted January 2, 2015

DOI: $10.3892 / \mathrm{mmr} .2015 .3273$

\begin{abstract}
MicroRNAs (miRs) have crucial functions in spermatogenesis and implications for male infertility. In the present study, Homo sapiens (hsa)-miR-145 was designed and cloned into the eukaryotic expression plasmid pGenesil-1. The recombinant plasmids were transfected into Hs 1.tes normal testicular cells and NTERA-2 testicular cancer cells. Quantitative polymerase chain reaction of hsa-miR-145 indicated that pGenesil-1-miR-145 effectively upregulated the expression of hsa-miR-145 in vitro. hsa-miR-145 overexpression inhibited the mRNA and protein expression of sex-determining region Y Box 9 in Hs 1.tes cells. The proliferation rates of NTERA-2 cells transfected with pGenesil-1-miR-145 were significantly decreased. High expression levels of miR-145 promoted cell apoptosis in NTERA-2 cells. The results revealed that altered hsa-miR-145 expression in testicular cells affects the regulation of target genes associated with male infertility.
\end{abstract}

\section{Introduction}

Approximately $12-15 \%$ of couples of reproductive age worldwide are sterile and approximately half of these cases are due to male factors (1). In at least one-third of male infertility cases, the cause is elusive (2) and is referred to as idiopathic infertility. Idiopathic male infertility predominantly manifests as oligozoospermia or azoopermia. When more than $30 \%$ of the spermatozoa have DNA damage, the fecundity of an individual decreases significantly in vivo. Thus, screening sperm

Correspondence to: Professor Xianping Ding, Bio-resource Research and Utilization Joint Key Laboratory of Sichuan-Chongqing, Institute of Medical Genetics, College of Life Science, Sichuan University, 29 Wangjiang Road, Wuhou, Chengdu, Sichuan 610064, P.R. China

E-mail: xianping2011@yeah.net

Key words: microRNA, human testicle cells, embryonic carcinoma of testis, male infertility for DNA damage is necessary in male patients with idiopathic infertility and patients pursuing assisted reproduction (3).

MicroRNAs (miRNAs/miRs) are non-coding RNA molecules approximately 22 nucleotides long, which regulate post-transcriptional gene expression by binding to the 3 ' untranslated region (UTR) of their target mRNA $(4,5)$. miRNAs affect a series of physiological activities involved in cell proliferation through their combination with target genes, causing mRNA degradation or translation inhibition. Recent studies in the field of reproduction indicate that miRNA is an important regulator of spermatogenesis. A study on the Dicer-dependent pathway demonstrated that miRNA loss has pernicious effects on male fertility (6). A further study indicated that Dicer-deleted primordial germ cells and spermatogonia exhibit proliferation disorders, and spermatogenesis is suppressed during the early stage of proliferation and early differentiation in Dicer-deleted testis (7). These studies suggested a role for certain miRNAs in reproduction. For instance, miR-383 is a negative regulator of cell proliferation, miR-383-pRb pathways are associated with spermatogenesis (8), and miRNA-372 and miR-373 are oncogenes in testicular germ cell tumors (9).

miR-145, located at 5q32-33, is an anti-oncogene, which targets several tumor-associated genes that are involved in tumor growth, metastasis and tumor angiogenesis. miR-145 regulates the expression of the pluripotency factors OCT4, sex-determining region Y Box (SOX)2 and -9 as well as KLF4, which also have oncogenic features (10). Sachdeva et al (11) reported that miR-145 inhibits the expression of proto-oncogene c-Myc via p53. Another study by Chiyomaru et al (12) illustrated that miR-145 expression is markedly restrained in tumor organization, wherein FSCN1 is overexpressed.

The transcription factor SOX9 is located at 17q24.3-q25.1 and is expressed in the heart, brain, kidneys, prostate, testicles and other organs in human adults. The SOX9 gene is expressed in the brain and testis, as well as during the resting or reproductive stages of the perichondrium of the fetus. SOX9 mutations are associated with sex reversal and SOX9 affects the development of bones and testicles through expression in mesoblastomas.

According to a report on miRNA chips, miR-145 is downregulated among altered miRNA in the testicular tissues of patients with non-obstructive azoospermia (NOA) (13). Among 
all species, miR-145 contains a unique seed sequence which is conserved in Xenopus, zebrafish and various mammals $(14,15)$. In living organisms, Homo sapiens (hsa)-miR-145 is abundant in the uterus, ovaries, testes, prostate and heart, which are all mesoderm-derived tissues (16). A previous study also revealed that SOX9 expression differs between normal and infertile samples based on DNA arrays, and SOX9 is required for Sertoli cell maturation and normal spermatogenesis (17). However, the association between SOX9 and miR-145 in reproductive cells has remained to be elucidated, and the function of hsa-miR-145 in human testes requires further study. In the present study, the testicular embryonic carcinoma cell line NTERA-2 (NT2) and a normal testis cell line, Hs 1.tes $(18,19)$ were used to investigate the function of hsa-miR-145 during spermatogenesis by identifying its target genes.

\section{Materials and methods}

Database analysis. Through miRBase (http://www.mirbase. org/) (20), it was confirmed that the sequence of hsa-miR-145 was 16-GUCCAGUUUUCCCAGGAAUCCCU-38. A search using TargetScan (http://www.targetscan.org/), miRBase and pictar (http://pictar.mdc-berlin.de/) revealed that the putative 3'UTR of SOX9 did not complement miR-145 (21) (Table I)."

Construction of miR-145 expression plasmid. A total of two single-stranded DNA sequences were designed based on the hsa-miR-145 sequence in the miRBase database. The hsa-miR-145 expression recombinant and a control plasmid were constructed by the cloning of annealed oligonucleotides of hsa-miR-145 (sense, 5'-GATCCCCGTCCAGTTTTCCCAGGAATCCCTTTTTTT GTCGACA-3' and antisense, 5'-AGCTTGTCGACAAAAAA AGGGATTCCTGGGAAAACTGGACGGG-3'), or control (sense, 5'-GATCCCCTTCTCCGAACGTGTCACGTATTA TTTTTTGTCGACA-3' and antisense, 5'-AGCTTGTCGACAA AAAATAATACGTGACACGTTCGGAGAAGGG-3') into pGenesil-1 plasmid. The recombinants were transformed into Escherichia coli DH5 $\alpha$ (TransGen, Beijing, China) competent cells, which were cultured in lysogeny broth (10 g/l tryptone, $5 \mathrm{~g} / 1$ yeast extract, $10 \mathrm{~g} / 1 \mathrm{NaCl}$; Beyotime Institute of Biotechnology, Shanghai, China) at $37^{\circ} \mathrm{C}$. Restriction enzymes SalI and PstI were used in the initial survey and DNA sequencing was conducted to identify the correct plasmid (22). DNA sequencing was completed by Sangon Biotech Co., Ltd (ABI3730xl; Shanghai, China).

Cell culture. NT-2 [American Type Culture Collection (ATCC), Manassas, VA, USA; CRL-1973 ${ }^{\mathrm{TM}}$ ] and Hs 1.tes (ATCC; CRL-7002 ${ }^{\mathrm{TM}}$ ) were grown in Dulbecco's modified Eagle's medium (DMEM; Hyclone, Logan, UT, USA) with high glucose, supplemented with $10 \%$ fetal bovine serum (FBS; Gibco-BRL, Gaithersburg, MD, USA) and 1\% antibiotics (100 U/ml penicillin and $100 \mathrm{mg} / \mathrm{ml}$ streptomycin). The cells were cultured at $37^{\circ} \mathrm{C}$ with $5 \% \mathrm{CO}_{2}$.

Recombinant plasmid transfection. Transfection of NT-2 and Hs 1.tes cells was performed using Lipofectamine 2000 reagent (Invitrogen Life Technologies, Carlsbad, CA, USA) according to the manufacturer's instructions. When the cell density in the six orifice plates reached $80 \%$, the cells were transfected with 5 ng pGenesil-1-miR-145 or 5 ng pGenesil-1-miR-NC in each orifice. The plasmids with pGenesil-1-miR-145 or pGenesil-1-miR-NC were extracted from E. coli using an Endofree plasmid minikit (Omega, Tarzana, CA, USA). Epifluorescence imaging of cells was carried out on an inverted epifluorescence microscope (Nikon Ti-E fluorescent microscope; Nikon, Tokyo, Japan). At $48 \mathrm{~h}$ after transfection, the cells were collected for RNA and protein extraction to be used for further analyses.

RNA isolation. Total RNA was isolated from the collected NT-2 or Hs 1.tes cells using a Total RNA kit II (Omega) according to the manufacturer's instructions. Spectrophotometry (Eppendorf BioSpectrometer ${ }^{\circledR}$ basic; Eppendorf, Hamburg, Germany) was used for RNA quantification. Optical density (OD) was measured at 260 and $280 \mathrm{~nm}$. The OD260/OD280 ratio was used to estimate RNA purity, and the RNA with OD ratios of 1.8-2.0 were used for subsequent studies (23).

miRNA detection. Reverse transcription quantitative polymerase chain reaction (RT-qPCR) analysis of miR-145 was performed in analogy with methods used in previous studies $(24,25)$. PCR was performed on cDNA generated from $2 \mu \mathrm{g}$ total RNA using the protocol of the All-in-One ${ }^{\mathrm{TM}}$ miRNA RT-qPCR Detection kit (GeneCopoeia, Rockville, $\mathrm{MD}, \mathrm{USA}$ ). A $25-\mu 1$ reaction mixture containing $2 \mu \mathrm{g}$ total RNA, $1 \mu 12.5 \mathrm{U} / \mu 1$ polymerase A, $1 \mu \mathrm{l}$ RTase mix and $5 \mu 1$ reaction buffer was prepared according to the manufacturer's instructions. The cycle parameters for the RT reaction were $37^{\circ} \mathrm{C}$ for $60 \mathrm{~min}$ and $85^{\circ} \mathrm{C}$ for $5 \mathrm{~min}$. Subsequently, $0.4 \mu \mathrm{RT}$ product was PCR-amplified in $20 \mu \mathrm{l}$ qPCR reaction mixture containing $10 \mu 12 \mathrm{X}$ All-in-One qPCR mix (GeneCopoeia), $0.2 \mu \mathrm{M}$ All-in-One qPCR Primer hsa-miR-145 (GeneCopoeia) and the hsnRNA U6 control (GeneCopoeia). The amplification parameters for RT and qPCR were set according to the manufacturer's instructions of the All-in-One miRNA RT-qPCR Detection kit using a Slan-96S real-time PCR system (Shanghai Hongshi Medical Technology Co., Ltd, Shanghai, China). The amplification parameters were as follows: $95^{\circ} \mathrm{C}$ for $3 \mathrm{~min}$, followed by 40 cycles of $95^{\circ} \mathrm{C}$ for $10 \mathrm{sec}, 60^{\circ} \mathrm{C}$ for $20 \mathrm{sec}$ and $72^{\circ} \mathrm{C}$ for $16 \mathrm{sec}$. hsnRNA U6 was used as a control to normalize the expression levels of each miRNA. The relative expression levels were obtained using the $2^{-\Delta \Delta \mathrm{CT}}$ method, with the relative gene expression $=2^{-(\Delta \mathrm{Ct} \text { sample }-\Delta \mathrm{Ct} \text { control })}$. All experiments were performed in triplicate.

RT-qPCR analysis. To determine the expression levels of SOX9 (NC_018928.1) in Hs 1.tes cells, RT-qPCR was performed using the All-in-One First-Strand cDNA Synthesis kit and All-in-One qPCR Mix (GeneCopoeia), followed by RT-qPCR using SYBR Green (GeneCopoeia). GAPDH (NM_002046.4) was used as the control. A $25-\mu 1$ reaction mixture containing $1 \mu \mathrm{g}$ total RNA, $10 \mu \mathrm{M}$ random primer, $1 \mathrm{U} / \mu 1 \mathrm{RNase}$ inhibitor, $8 \mathrm{U} / \mu \mathrm{l}$ M-MLV RTase, $1 \mathrm{mM} \mathrm{dNTP}$ and $5 \mu \mathrm{l}$ reaction buffer was prepared according to the manufacturer's instructions. The cycling parameters for the RT reaction were $37^{\circ} \mathrm{C}$ for $60 \mathrm{~min}$ and $85^{\circ} \mathrm{C}$ for $5 \mathrm{~min}$. Subsequently, a reaction mixture containing $10 \mu \mathrm{l} 2 \mathrm{X}$ All-in-One qPCR Mix and the appropriate primers was added to $2 \mu \mathrm{l}$ cDNA template to a final reaction volume of $20 \mu \mathrm{l}$. The amplification parameters 
Table I. Target validation of the SOX9 3'UTRs by TargetScan, miRBase and Pictar.

\begin{tabular}{lll}
\hline Gene & Target sites & Position \\
\hline SOX9 & $5^{\prime} \ldots$ UUUUUGUUGAAAACAAACUGGAA & $1402-1409$ \\
& $3^{\prime} \ldots . .$. UCCCUAAGGACCCUUUUGACCUG & \\
\hline
\end{tabular}

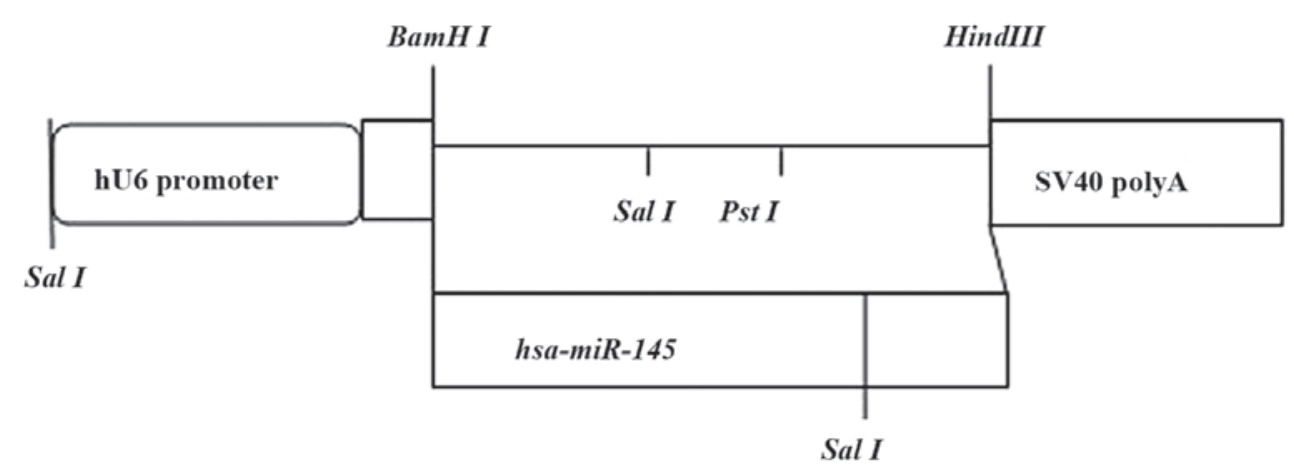

Figure 1. Structure of plasmid pGenesil-1 vector. miR-145 or control sense encoding template was inserted between the HindIII and BamHI restriction sites. hsa, Homo sapiens; miR, microRNA; polyA, polymerase A.

were $95^{\circ} \mathrm{C}$ for $5 \mathrm{~min}$, followed by 30 cycles of $95^{\circ} \mathrm{C}$ for $10 \mathrm{sec}$, $62.8^{\circ} \mathrm{C}$ for $20 \mathrm{sec}$ and $72^{\circ} \mathrm{C}$ for $16 \mathrm{sec}$. PCR was performed using a Slan-96S real-time PCR system. Data were analyzed using the $2^{-\triangle \Delta C T}$ method. The primers (Sangon Biotech Co., Ltd) used for RT-qPCR were as follows: SOX9 forward, 5'-TGGTCTTTAACTCTGACCGTTACCT-3' and reverse, 5'-TATTCCGGATCTTAATCAGAGAAAGTG-3'; GAPDH forward, 5'-ACGGATTTGGTCGTATTGGGC-3' and reverse, 5'-CTCGCTCCTGGAAGATGGTGAT-3'.

The expression levels of OCT4 (GenBank ID, NM_002701.4), SOX2 (NM_003106.3), c-Myc (NM_002467.4), KLF4 (NM_004235.4) and FSCN1 (NM_003088.3) in NT-2 cells were determined using an All-in-One First-Strand cDNA synthesis kit and an All-in-One qPCR mix (GeneCopoeia). The RT reaction and RT-qPCR were operated as described above. The melting temperature for OCT4, SOX2, c-Myc and KLF4 was $60^{\circ} \mathrm{C}$ and the melting temperature for FSCN1 was $65^{\circ} \mathrm{C}$. GAPDH was used as a control and data were analyzed using the $2^{-\Delta \Delta \mathrm{CT}}$ method. The primers (Sangon Biotech Co., Ltd) used for RT-qPCR were as follows: OCT4 forward, 5'-CTGGGTTGATCCTCGGACCT-3' and reverse, 5'-CACAGAACTCATACGGCGGG-3'; SOX2 forward, 5'-CCCAGCAGACTTCACATGT-3' and reverse, 5'-CCTCCCATTTCCCTCGTTTT-3'; с-Мyс forward, 5'-CGTCTCCACACATCAGCACAA-3' and reverse, 5'-TCTTGGCAGCAGGATAGTCCTT-3'; KLF4 forward, 5'-CAGCTCCCCAGCAGGACTACC-3' and reverse, 5'-CATCTGAGCGGGCGAATTTC-3'; FSCN1 forward, 5'-CTGGCTACACGCTGGAGTTC-3' and reverse, 5'-CTGAGTCCCCTGCTGTCTCC-3'. All experiments were performed in triplicate.

Western blot analysis. GAPDH was used as the internal control. The cell lysates were used for protein extraction. Infected cells were washed three times with ice-cold phosphate-buffered saline (Beyotime Institute of Biotechnology) and the cells were resuspended in $100 \mu 1$ radioimmunoprecipitation assay buffer (Beyotime Institute of Biotechnology). Cells were incubated on ice for $30 \mathrm{~min}$, centrifuged at 15,000 x g and the supernatant was collected. Following measuring the protein concentration using an ELISA, the equivalent denatured protein samples were mixed with loading buffer. The samples were resolved using 10\% SDS-PAGE and transferred onto a polyvinylidene fluoride membrane via the wet transfer method. Following blocking for $1 \mathrm{~h}$ in $5 \%$ nonfat dried milk (Yili Industrial Group Co., Ltd, Inner Mongolia, China) in Tris-buffered saline and Tween 20 (TBST; Amresco, Solon, $\mathrm{OH}, \mathrm{USA}$ ) at room temperature, the blots were incubated overnight with rabbit polyclonal anti-SOX9 (BS1597; Bioworld Technology, Nanjing, China; diluted 1:1,000) or mouse monoclonal anti-GAPDH (200306; Zen Bioscience, Chengdu, China; diluted 1:5,000) antibodies at $4^{\circ} \mathrm{C}$ for 15 . Following washing three times in TBST, the blots were incubated with horseradish peroxidase (HRP)-conjugated secondary antibodies (Santa Cruz Biotechnology, Inc., Santa Cruz, CA, USA; diluted 1:2,000) at room temperature for $1 \mathrm{~h}$. The blots were visualized using Immobilon Western chemiluminescent HRP substrate (Millipore, Billerica, MA, USA) following the manufacturer's instructions. A Kodak 440CF imaging system (Kodak, Tokyo, Japan) was used to visualize the blots.

Cell proliferation assay. Growth inhibition of NT-2 cells was determined via MTT cell viability assays using MTT Cell Proliferation kit (Solarbio, Beijing, China). The NT-2 cells were cultured in 96-well plates at an initial number of $1 \times 10^{4}$ cells/well in DMEM supplemented with $10 \%$ FBS. Following transfecting the recombinant plasmids for $48 \mathrm{~h}$ at $37^{\circ} \mathrm{C}, 10 \mu \mathrm{l}$ MTT reagent was added and allowed to react for $4 \mathrm{~h}$ in an incubator. A total of $110 \mu \mathrm{l}$ formazan reagent was added, which was allowed to react for $10 \mathrm{~min}$. Substrate cleavage was monitored at $490 \mathrm{~nm}$ via ELISA. Experiments were performed in triplicate. 


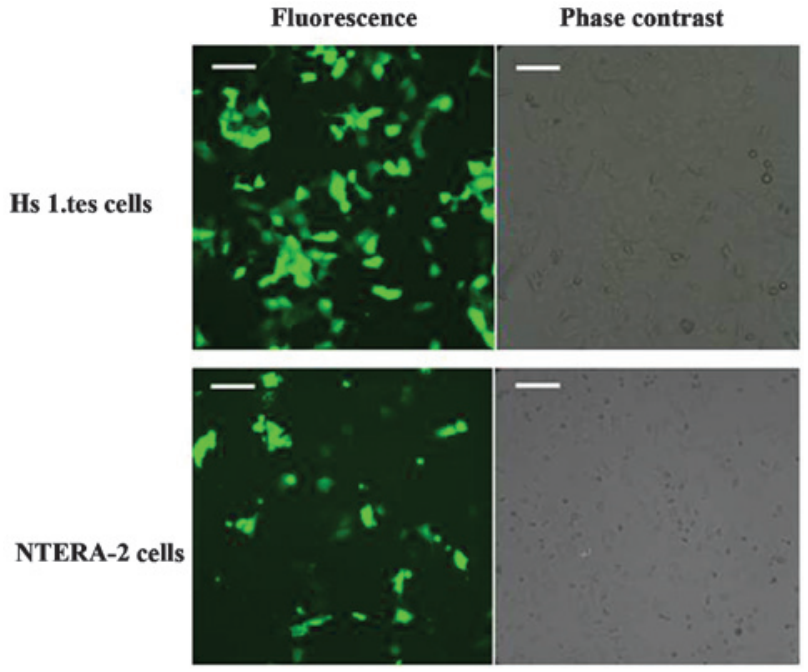

Figure 2. Fluorescent and light microscopy images of Hs 1.tes cells and NT-2 cells within $24 \mathrm{~h}$ after transfection. Scale bar, $100 \mu \mathrm{m}$.

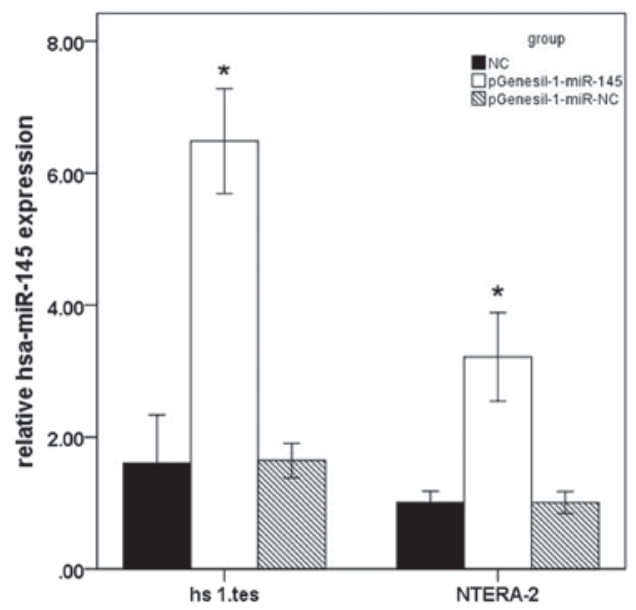

Figure 3. Relative miR-145 levels in NT-2 cells and in Hs 1.tes cells. Transfection was performed for $48 \mathrm{~h}$. Three independent experiments were performed and values are expressed as the mean \pm standard deviation. "P $<0.05$, compared with the NC. NC, negative control; miR, microRNA; hsa, Homo sapiens.

Cell apoptosis assay. Cell apoptosis was detected using Annexin V-allophycocyanin (APC)/7-aminoactinomycin D (7-AAD) double staining and flow cytometric analysis. NT-2 cells were cultured in six-well plates. The NT-2 cells were transfected with pGenesil-1-miR-145 and pGenesil-1-miR-NC. After $48 \mathrm{~h}$, the cells were collected and manipulated according to the instructions of the Annexin V-APC/7-AAD apoptosis detection kit (KeyGen Biotech Co., Ltd, Nanjing, China). A total of $500 \mu$ l binding buffer was added to make a cell suspension. $5 \mu \mathrm{l}$ Annexin V-APC was added, followed by $5 \mu 1$ 7-AAD. The mixture was allowed to react in the dark for $15 \mathrm{~min}$ at room temperature. After $1 \mathrm{~h}$, the mixture was analyzed via flow cytometry (BD FACSCalibur; BD Biosciences, San Jose, CA, USA).

Statistical analysis. The data were analyzed using SPSS 19.0 software (IBM, Armonk, NY, USA). A t-test was used for statistical comparisons between groups, whereas a one-way

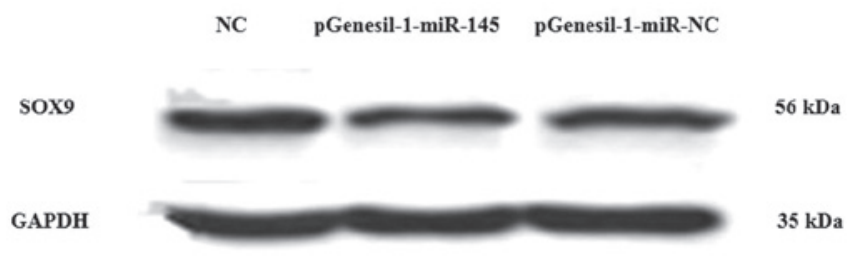

Figure 4. Hs 1.tes cells were transfected with pGenesil-1-miR-145 or pGenesil-1-miR-NC for $48 \mathrm{~h}$. Cells of transfection groups and control were harvested for measurement of SOX9 protein expression using Western blotting. GAPDH was used as an internal control. Quantitation of the SOX9 protein level was performed using Quantity One software. SOX9, sex-determining region $\mathrm{Y}$ Box gene 9; NC, negative control.

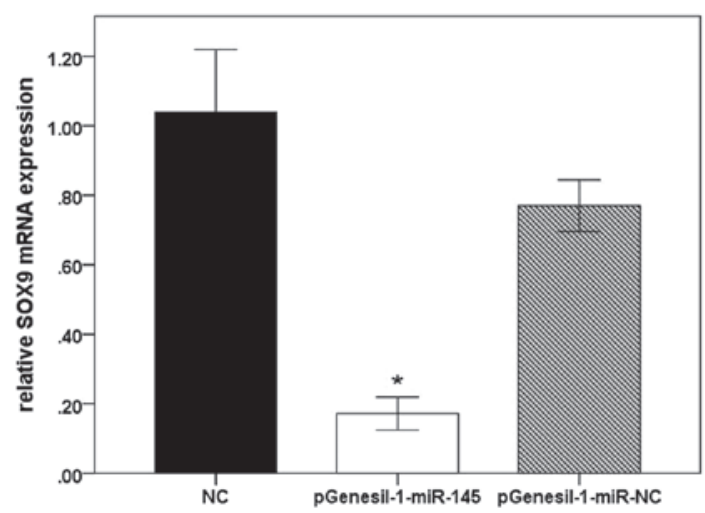

Figure 5. Hs 1.tes cells transfected with pGenesil-1-miR-145, pGenesil-1-miR-NC and following $48 \mathrm{~h}$, mRNA levels of SOX9 were measured using reverse-transcription quantitative polymerase chain reaction. GAPDH was used as an internal control. Three independent experiments were performed and values are expressed as the mean \pm standard deviation. ${ }^{*} \mathrm{P}<0.05$, compared with the NC. NC, negative control; miR, microRNA.

analysis of variance was used for comparisons among multiple groups. $\mathrm{P}<0.05$ was considered to indicate a statistically significant difference.

\section{Results}

Identification of miR-145 expression vector and control construct. Plasmid pGenesil-1 is a eukaryotic expression vector containing a U6 promoter, an enhanced green fluorescent protein (EGFP) gene and an anti-kanamycin gene. Multiple cloning sites were located behind U6, including the restriction enzyme sites BamHI, HindIII, SalI, and PstI. SalI and PstI are between BamHI and HindIII. Double digestion was used with restriction enzymes BamHI and HindIII to obtain a linear fragment, which was inserted into SalI to verify the recombinant plasmids (Fig. 1). The correct plasmid was identified via electrophoresis. Sall digestion produced a 350-bp fragment, whereas Pst I digestion did not. DNA sequencing confirmed that the plasmids were reconstructed successfully. The samples were retested through sequencing by Sangon Biotech (Shanghai, China).

Transfection. The pGenesil-1-miR-145 and pGenesil-1-control constructs with enhanced green florescence protein were transfected into the NT-2 cell line and the Hs 1.tes cell line, respectively. The constructs exhibited green fluorescence 
Table II. Expression levels of OCT4, SOX2, c-Myc, KLF4 and FSCN1 mRNA.

\begin{tabular}{lccc}
\hline Gene/group & NC & pGenesil-1-miR-145 & pGenesil-1-miR-NC \\
\hline OCT4 & $1.00 \pm 0.14$ & $0.60 \pm 0.15^{\mathrm{a}}$ & $0.80 \pm 0.05$ \\
SOX2 & $1.11 \pm 0.29$ & $0.22 \pm 0.05^{\mathrm{a}}$ & $0.84 \pm 0.10$ \\
c-Myc & $1.00 \pm 0.07$ & $0.43 \pm 0.14^{\mathrm{a}}$ & $0.89 \pm 0.14$ \\
KLF4 & $1.02 \pm 0.24$ & $0.78 \pm 0.15$ & $0.97 \pm 0.27$ \\
FSCN1 & $1.01 \pm 0.21$ & $0.15 \pm 0.08^{\mathrm{a}}$ & $0.99 \pm 0.17$
\end{tabular}

NTERA-2 cells were transfected with pGenesil-1-miR-145, pGenesil-1-miR-NC and then mRNA levels were measured using reverse transcription quantitative polymerase chain reaction at $48 \mathrm{~h}$. GAPDH was used as an internal control. Three independent experiments were performed and values are expressed as the mean \pm standard deviation. ${ }^{a} \mathrm{P}<0.05$, compared with the NC. NC, negative control.

Table III. NTERA-2 cell proliferation inhibition by transfection with recombinants for $48 \mathrm{~h}$.

\begin{tabular}{lcr}
\hline Group & Absorbance (A) & Inhibition ratio \\
\hline NC & $0.22 \pm 0.07$ & - \\
pGenesil-1-miR-145 & $0.12 \pm 0.03^{\mathrm{a}}$ & $45.45 \%$ \\
pGenesil-1-miR-NC & $0.21 \pm 0.09$ & $4.45 \%$
\end{tabular}

Inhibition ratio=(1-average absorption value in experimental group/average absorption value in NC group)x $100 \%$. Values are expressed as the mean \pm standard deviation of nine experiments. ${ }^{\mathrm{a}} \mathrm{P}<0.05$, when compared with the NC. NC, negative control.
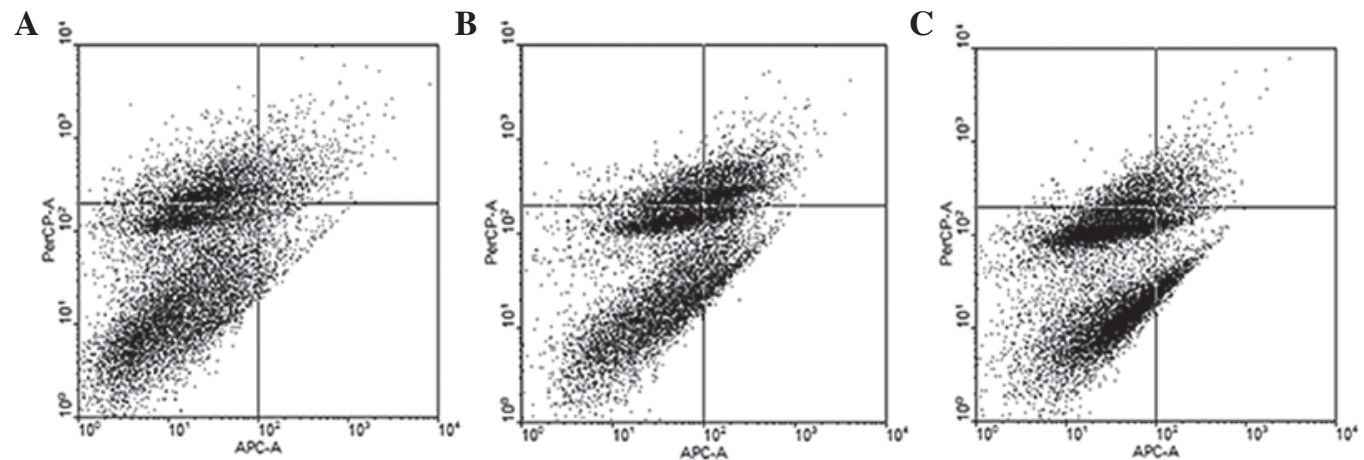

Figure 6. Assessment of apoptotic rates using Annexin V-APC/7-AAD double staining and flow cytometric analysis. (A) NC (normal controls) group. (B) pGenesil-1-miRNA-145 group. (C) pGenesil-1-NC group. (X axis indicates APC staining for viable apoptotic cells, and the Y axis indicates 7-AAD staining for non-viable apoptotic cells). APC, allophycocyanin; 7-AAD, 7-aminoactinomycin D.

under inverted fluorescence microscopy. Fluorescence was observed under fluorescence microscopy in cells containing pGenesil-1-miR-145 and pGenesil-1-miR-NC within $24 \mathrm{~h}$ after transfection. No fluorescent signal was observed in the blank control group (Fig. 2).

miR-145 overexpression in pGenesil-1-miR-145-transfected cells. The pGenesil-1-miR-145-transfected groups and pGenesil-1-miR-NC-transfected groups were analyzed at $48 \mathrm{~h}$ after transfection. miR-145 expression of the NT-2 and Hs 1.tes cells in the control and the transfected groups were analyzed via RT-qPCR (Fig. 3). The mRNA levels were normalized to the internal control U6. Statistical analysis revealed that the miR-145 expression levels in the NT-2 and Hs 1.tes cells in pGenesil-1-miR-145 groups were higher than those in the control and the pGenesil-1-miR-NC groups $(\mathrm{P}<0.05)$.
pGenesil-1-miR-NC had no effect on miR-145 expression in NT-2 and Hs 1.tes cells ( $\mathrm{P}>0.05$, vs. control).

miR-145 inhibits SOX9 expression in Hs 1.tes cells at the $m R N A$ and protein level. To demonstrate that miR-145 acts as an inhibitor of SOX9 protein expression, pGenesil-1-miR-145 and pGenesil-1-miR-NC were transfected into Hs 1.tes cells. Western blot analysis revealed that SOX9 protein levels were markedly lower in the cells with miR-145 overexpression than those in the negative control (Fig. 4). The relative protein expression of SOX9 in Hs 1.tes cells was as follows: NC group, 0.88 \pm 0.02 ; pGenesil-1-miR-145 group, 0.59 \pm 0.01 ; and pGenesil-1-miR-NC group, 0.82 \pm 0.03 . RT-qPCR analysis demonstrated that the SOX9 mRNA levels were decreased in the cells with miR-145 overexpression (Fig. 5). The relative mRNA expression of SOX9 in Hs 1.tes cells 
was as follows: NC group, $1.03 \pm 0.73$; pGenesil-1-miR-145 group, $0.17 \pm 0.02$; and pGenesil-1-miR-NC group, $0.77 \pm 0.03$. SOX9 had no marked change in the mRNA and protein levels in the pGenesil-1-miR-NC-transfected cells. Thus, the results demonstrated that miR-145 inhibited the protein and mRNA expression of SOX9 in Hs 1.tes cells.

miR-145 inhibits the expression of OCT4, SOX2, c-Myc, KLF4, and FSCN1 at the mRNA level in NT-2 cells. To investigate the effect of miR-145 in germ cell neoplasms, it was determined whether miR-145 inhibited the expression of endogenous OCT4, SOX2, KLF4, c-Myc and FSCN1 in NT-2 cells. miR-145 was upregulated and the mRNA levels of these genes among three groups were detected. RT-qPCR revealed that the mRNA levels of OCT4, SOX2, c-Myc and FSCN1, but not KLF4, were decreased in the pGenesil-1-miR-145 group (Table II). However, no significant differences were detected in the expression of these genes in pGenesil-1-miR-NC-transfected cells.

Inhibition of proliferation by miR-145 in NT-2 cells. To analyze the biological effect of upregulated miR-145 expression, the growth of NT-2 cells treated with pGenesil-1-miR-145 was investigated using an MTT assay (Table III). At $48 \mathrm{~h}$ after transfection, it was observed that pGenesil-1-miR-145 significantly reduced the growth of Hs 1.tes and NT-2 cells. By contrast, the growth in the control group exhibited no significant changes.

Promotion of NT-2 cell apoptosis by miR-145. The results of the flow cytometric analysis are shown in Fig. 6. The apoptotic rate was $9.53 \pm 0.63 \%$ in the NC group, $30.22 \pm 0.56 \%$ in the pGenesil-1-miR-145 group and $12.54 \pm 1.89 \%$ in the pGenesil-1-miR-NC group. The apoptotic rate was significantly higher in the pGenesil-1-miR-145 group compared with that in the $\mathrm{NC}$ group.

\section{Discussion}

miRNAs are small, endogenous molecular regulators of gene expression that have critical roles in the body $(26,27)$. In early studies on the biological characteristics of miRNAs, the pH1-RNApuro plasmid was used as a recombinant construct for upregulating miRNA expression (22). The pGenesil-1 plasmid was selected, which carries a U6 promoter, a kanamycin resistance gene and an EGFP gene, which is used for selection following transfection. The structure of pGenesil-1-miR-145 was determined via DNA sequencing and restriction enzyme digestion. RT-qPCR detection indicated that miR-145 is upregulated in the pGenesil-1-miR-145-transfected group, which suggested that pGenesil-1-miR-145 should be used for further investigation.

Spermatogenesis is a complex process, which involves the development of spermatogonial stem cells into highly differentiated spermatozoon. This process includes two stages: Active proliferation of spermatogonia and meiosis of spermatocytes. Certain studies have demonstrated the accelerated germ cell apoptosis and decreased mitotic activity of spermatogonia in infertile men during the spermatocyte stage $(28,29)$. A recent study revealed that normal active spermatogonia in testes are arrested at the pachytene stage (30). This spermatogenic failure may be due to meiotic failure, but the mechanism of genetic defects in spermatogenesis remains to be elucidated (31). A microarray assay was used to demonstrate the altered expression of different miRNAs, including miR-145 in the testes of patients with NOA. The microarray assay revealed that aberrant miRNA expression is associated with male infertility. As a fertility biomarker, comparison of the DNA array of abnormal human testis samples with normal human testis samples exhibited SOX9 gene overexpression (17). The transcription factor SOX9, which is required for Sertoli cell maturation and normal spermatogenesis, regulates steroidogenic factor-1 promoter activity in Sertoli cells (32). Studies on chondrogenic differentiation demonstrate that miR-145 is a negative regulator through directly targeting SOX9 during the early stage of chondrogenic differentiation (33). Altered hsa-miR-145 expression in testicular cells is involved in the regulation of target genes associated with male infertility. In the present study, recombinant plasmids were constructed, which express pGenesil-1-miR-145 to transfect normal Hs 1.tes cells. The results of the RT-qPCR and western blot analyses demonstrated that miR-145 suppressed SOX9 mRNA and protein expression in transiently transfected Hs 1 .tes cells compared with that in pGenesil-1-miR-NC-mediated cells and untreated Hs 1.tes cells $(\mathrm{P}<0.05)$. The present results coincide with those of previous studies, which indicated that miR-145 downregulates SOX9 protein expression. SOX9 mRNA expression was also decreased in the present study. miR-145 inhibition during SOX9 transcription was greater than that during translation. This difference may be due to miR-145 regulating the expression of numerous genes, which subsequently inTERAct with SOX9.

Previous studies have revealed that miR-145 is downregulated in numerous types of human cancer and its transfection reduces cell proliferation in tumor cell lines (34-39). Earlier studies revealed that miR-145 directly targets the proto-oncogene c-Myc and insulin receptor substrate-1, which are associated with cell proliferation $(11,40)$. In bladder cancer, miR-145 directly controls FSCN1, which functions mainly in cortical cell protrusions, which mediate inTERActions between cells and the extracellular matrix, cell-to-cell inTERActions and cell migration. FSCN1 also forms cytoplasmic microfilamentous bundles, which contribute to cell architecture and intracellular movements (12). In the present study, pGenesil-1-miR-145 was transfected into NT-2 cells and it was demonstrated that miR-145 overexpression significantly reduces the growth of NT-2 cells. Flow cytometric analysis revealed that the apoptotic rate increased in the pGenesil-1-miR-145 group. RT-qPCR revealed that the mRNA levels of c-Myc and FSCN1 decreased in the pGenesil-1-miR-145 transfection group.

miR-145s function by directly targeting the pluripotency factors OCT4, SOX2 and KLF4 to inhibit the pluripotency of stem cells and control embryonic stem cell differentiation. miR-145 and OCT4 form a double-negative feedback loop and the promoter of miR-145 is inhibited by OCT4 $(10,41)$. In the present study, RT-qPCR revealed that miR-145 inhibited the mRNA expression of OCT4 and SOX2, but not that of KLF4. Earlier studies revealed that the genes, which preserve 
stem cell properties, including OCT4, SOX2, KLF4 and Nanog, have oncogenic characteristics and are involved in tumor development. These results demonstrated that miR-145 directly regulates the biological properties of tumor cells, as well as regulating cancer stem cells.

In conclusion, recombinant $\mathrm{pGenesil-1-miR-145} \mathrm{significantly}$ inhibited the mRNA and protein expression of SOX9 in human testicular cells. These data have important implications in studies on spermatogenesis. Differentially expressed molecules may be used as biomarkers to provide insights into the mechanisms underlying male infertility. The results of the present study may assist in developing a gene therapy for azoospermia. miR-145 inhibits the expression of oncogenes, such as OCT4, SOX2, c-Myc and FSCN1, as well as the proliferation of testicular embryonal carcinoma cells. Thus, upregulating miR-145 expression is a potential alternative treatment for testicular germ cell tumors. Further investigation into the inTERActions of miR-145 with other target genes are required to understand the occurrence and development of spermatogenesis and the suppression of malignant germ cell tumors.

\section{Acknowledgements}

The authors are grateful to Dr Liu Ying and Dr Sun Huaqin in the Joint Laboratory for Reproductive Medicine of Sichuan University - The Chinese University of Hong Kong. The present study was supported by funds from the Science and Technology Department of Sichuan Province, China.

\section{References}

1. Zhu YJ, Liu SY, Wang H, Wei P and Ding XP: The prevalence of azoospermia factor microdeletion on the Y chromosome of Chinese infertile men detected by multi-analyte suspension array technology. Asian J Androl 10: 873-881, 2008.

2. Evenson DP, Larson KJ and Jost LK: Sperm chromatin structure assay: its clinical use for detecting sperm DNA fragmentation in male infertility and comparisons with other techniques. J Androl 23: 25-43, 2002.

3. Agarwal A and Said TM: Role of sperm chromatin abnormalities and DNA damage in male infertility. Hum Reprod Update 9: 331-345, 2003.

4. Bartel DP: MicroRNAs: genomics, biogenesis, mechanism and function. Cell 116: 281-297, 2004.

5. Stark A, Bushati N, Jan CH, Kheradpour P, Hodges E, Brennecke $\mathrm{J}$ and Kellis M: A single Hox locus in Drosophila produces functional microRNAs from opposite DNA strands. Genes Dev 22: 8-13, 2008.

6. Papaioannou MD and Nef S: microRNAs in the testis: Building up male fertility. J Androl 31: 26-33, 2010.

7. Hayashi K, Chava de Sousa Lopes SM, Kaneda M, Tang F, Hanjkova P, Lao K, Surani MA, et al: MicroRNA biogenesis is required for mouse primordial germ cell development and spermatogenesis. PLoS One 3: e1738, 2008.

8. Lian J, Tian H, Liu L, Zhang XS, Li WQ, Deng YM and Sun F: Downregulation of microRNA-383 is associated with male infertility and promotes testicular embryonal carcinoma cell proliferation by targeting IRF1. Cell Death Dis 1: e94, 2010.

9. Voorhoeve PM, le Sage C, Schrier M, Gillis AJ, Stoop N, Nagel R and Agami R, et al: A genetic screen implicates miRNA-372 and miRNA-373 as oncogenes in testicular germ cell tumors. Cell 124: 1169-1181, 2006.

10. Xu N, Papagiannakopoulos T, Pan G, Thomson JA and Kosik KS: MicroRNA-145 regulates OCT4, SOX2 and KLF4 and represses pluripotency in hum an embryonic stem cell. Cell 137: 647-658, 2009.

11. Sachdeva M, Zhu S, Wu F, Walia V, Kumar S, Elble R, Watabe K and Mo YY: p53 represses c-Myc through induction of the tumor suppressor miR-145.Proc Natl Acad Sci USA 106: 3207-3212, 2009.
12. Chiyomaru T, Enokida H, Tatarano S, Kawahara K, Uchiada Y, Nishiyama K, Fujimura L, Kikkawa N, Seki N and Nakagawa M: miR-145 and miR-133a function as tumour suppressors and directly regulate FSCN1 expression in bladder cancer. Br J Cancer 102: 883-891, 2010.

13. Lian J, Zhang X, Tian H, Liang N, Wang Y, Liang CZ, Li X and Sun F: Altered microRNA expression in patients with non-obstructive azoospermia. Reprod Biol Endocrinol 7: 13, 2009.

14. Lagos-Quintana M, Rauhut R, Lendeckel W and Tuschl T: Identification of novel genes coding for small expressed RNAs. Science 294: 853-858, 2001.

15. Michael MZ, O'Connor SM, van Holst Pellekaan NG, Young GP and James RJ: Reduced accumulation of specific MicroRNAs in colorectal neoplasia1. Mol Cancer Res 1: 882-891, 2003.

16. Landgraf P, Rusu M, Sheridan R, Sewer A, Iovino N, Aravin A, Pfeffer S, Rice A, Kamphorst AO, Landthaler M, et al: A mammalian microRNA expression atlas based on small RNA library sequencing. Cell 129: 1401-1414, 2007.

17. Rockett JC, Patrizio P, Schmid JE, Hecht NB and Dix DJ: Gene expression patterns associated with infertility in humans and rodent models. Mutat Res 549: 225-240, 2004.

18. Lee VM and Andrews PW: Differentiation of NTERA-2 clonal human embryonal carcinoma cells into neurons involves the induction of all three neurofilament proteins. J Neurosci 6: 514-521, 1986.

19. Kumi-Diaka J, Hassanhi M, Brown J, Merchant K, Garcia C and Jimenez W: CytoregR inhibits growth and proliferation of human adenocarcinoma cells via induction of apoptosis. J Carcinog 5: 1, 2006.

20. Griffiths-Jones S and Grocock RJ: van Dongen S, Bateman A and Enright AJ: miRBase: microRNA sequences, targets and gene nomenclature. Nucleic Acids Res 34: 140-144, 2006.

21. Lewis BP, Shih IH, Jones-Rhoades MW, Bartel DP and Burge CB: Prediction of mammalian microRNA targets. Cell 115: 787-798, 2003.

22. Takamizawa J, Konishi H, Yanagisawa K, Tomida S, Osada H, Endoh H, Harano T, Yatabe Y, Nagino M, Nimura Y, Mitsudomi T and Takahashi T: Reduced expression of the let-7 microRNAs in human lung cancers in association with shortened postoperative survival. Cancer Res 64: 3753-3756, 2004.

23. Cho WC, Chow AS and Au JS: Restoration of tumour suppressor hsa-miR-145 inhibits cancer cell growth in lung adenocarcinoma patients with epidermal growth factor receptor mutation. Eur J Cancer 45: 2197-2206, 2009.

24. Jung YH, Gupta MK, Shin JY, Uhm SJ and Lee HT: MicroRNA signature in testes-derived male germ-line stem cells. Mol Hum Reprod 16: 804-810, 2010.

25. Cheng Y, Liu X, Yang J, Lin Y, Xu DZ, Lu Q, Deitch EA, Huo YQ, Delphin ES and Zhang C: MicroRNA-145, a novel smooth muscle cell phenotypic marker and modulator, controls vascular neointimal lesion formation. Circ Res 105: 158-166, 2009.

26. Vamsi K, Gangaraju and Haifan Lin: MicroRNAs: key regulators of stem cells. Nat Rev Mol Cell Bio 10: 116-125, 2009.

27. Lakshmipathy U and Hart RP: Concise review: MicroRNA expression in multipotent mesenchymal stromal cells. Stem Cells 26: 356-363, 2008

28. Lin WW, Lamb DJ, Lipshultz LI and Kim ED: Demonstration of testicular apoptosis in human male infertility states using a DNA laddering technique. Int Urol Nephrol 31: 361-370, 1999.

29. Steger K, Aleithe I, Behre H, Bergmann M: The proliferation of spermatogonia in normal and pathological human seminiferous epithelium: an immunohistochemical study using monoclonal antibodies against Ki-67 protein and proliferating cell nuclear antigen. Mol Hum Reprod 4: 227-233, 1998.

30. Bar-Shira Maymon B, Yogev L, Yavetz H, Lifschitz-Mercer B, Schreiber L, Kleiman SE, Botchan A, Hauser R and Paz G: Spermatogonial proliferation patterns in men with azoospermia of different etiologies. Fertil Steril 80: 1175-1180, 2003.

31. Gonsalves J, Sun F, Schlegel PN, Turek PJ, Hopps CV, Greene C, Martin RH and Pera RA: Defective recombination in infertile men. Hum Mol Genet 13: 2875-2883, 2004.

32. Schumacher V, Gueler B, Looijenga LH, Becker JU, Amann K, Engers R, Dotsch J, Stoop H, Schulz W and Royer-Pokora B: Characteristics of testicular dysgenesis syndrome and decreased expression of SRY and SOX9 in frasier syndrome regulation of the orphan nuclear receptor steroidogenic factor 1 by sox proteins. Mol Reprod Dev 75: 1484-1494, 2008. 
33. Yang B, Guo H, Zhang Y, Chen L, Ying D and Dong S: MicroRNA-145 regulates chondrogenic differentiation of mesenchymal stem cells by targeting SOX9. PLoS One 6: e21679, 2011.

34. Bandrés E, Cubedo E, Agirre X, Malumbres R, Zarate R, Ramirez N, Abajo A, Navarro A, Moreno I, Monzo M and Garcia-Foncillas J: Identification by real-time PCR of 13 mature microRNAs differentially expressed in colorectal cancer and non-tumoral tissues. Mol Cancer 5: 29, 2006.

35. Sempere LF, Christensen M, Silahtaroglu A, Bak M, Heath CV Schwartz G, Wells W, Kauppinen S and Cole CN: Altered microRNA expression confined to specific epithelial cell subpopulations in breast cancer. Cancer Res 67: 11612-11620, 2007.

36. Slaby O, Svoboda M, Fabian P, Smerdova T, Knoflickova D, Bednarikova M, Nenutil R and Vyzula R: Altered expression of miR-21, miR-31, miR-143 and miR-145 is related to clinicopathologic features of colorectal cancer. Oncology 72: 397-402, 2007.
37. Szafranska AE, Davison TS, John J, Cannon T, Sipos B, Maghnouj A, Labourier E and Hahn SA: MicroRNA expression alTER Ations are linked to tumorigenesis and non-neoplastic processes in pancreatic ductal adenocarcinoma. Oncogene 26: 4442-4452, 2007.

38. Ozen M, Creighton CJ, Ozdemir M and Ittmann M: Widespread deregulation of microRNA expression in human prostate cancer. Oncogene 27: 1788-1793, 2008.

39. Wang X, Tang S, Le SY, Lu R, Rader JS, Meyers C and Zheng ZM: Aberrant expression of oncogenic and tumor-suppressive microRNAs in cervical cancer is required for cancer cell growth. PLoS One 3: e2557, 2008.

40. Shi B, Sepp-Lorenzino L, Prisco M, Linsley P, deAngelis T and Baserga R: MicroRNA-145 targets the insulin receptor substrate- 1 and inhibits the growth of colon cancer cells. J Biol Chem 282: 32582-32590, 2007.

41. Tay Y, Zhang J, Thomson AM, Lim B, and Rigoutsos I: MicroRNAs to Nanog, Oct 4 and Sox 2 coding regions modulate embryonic stem cell differentiation. Nature 455: 1124-1128, 2008 